\title{
Block Copolymer-Directed Assembly of Nanoparticles: Forming Mesoscopically Ordered Hybrid Materials
}

\author{
Russell B. Thompson, ${ }^{\dagger}$ Valeriy V. Ginzburg, ${ }^{\dagger \neq}$ Mark W. Matsen, ${ }^{\S}$ and \\ Anna C. Balazs*,†
}

Department of Chemical and Petroleum Engineering, University of Pittsburgh, Pittsburgh, Pennsylvania 15261; and Polymer Science Centre, University of Reading, Whiteknights, Reading RG6 6AF, United Kingdom

Received September 4, 2001; Revised Manuscript Received October 24, 2001

\begin{abstract}
Mixtures of diblock copolymers and nanoscopic spherical particles can yield well-ordered hybrid materials, which can be used for separation processes, catalysis, and optoelectronic applications. Predicting the morphologies of these systems is difficult because the final structures depend not only on the characteristics of the copolymer but also on the features of the particles. Combining self-consistent field and density functional theories, we develop a model that allows us to determine the equilibrium or metastable phases of diblock copolymer/spherical nanoparticle composites, without making a priori assumptions about the structure of the system. Using this model, we illustrate various examples where mixtures of diblocks and nanoparticles self-assemble into mesoscopically ordered phases. The model can be generalized to other types of copolymers and particles and can be modified to include homopolymers or solvent molecules. Thus, the technique constitutes a useful tool for determining the structures of a large class of nanocomposites.
\end{abstract}

\section{Introduction}

Composite materials that are composed of polymers and inorganic filler particles offer a variety of benefits over pure polymer systems. These advantages can include increased strength, decreased gas permeability, improved heat resistance, and enhanced electrical conductivity. ${ }^{1-4}$ Recently, there has been considerable interest in developing filled systems where the polymeric component is a block copolymer. In principle, the microphase separation of the block copolymers could be harnessed to promote the ordering of the particles and thereby create highly organized hybrid materials. Such spatially regular composites could potentially be used in separation processes, as the next-generation catalysts and as photonic band gap materials..$^{5-7}$ The directed self-assembly of the copolymers and particles could also be exploited to create materials inspired by nature. ${ }^{8} \mathrm{~F}$ or example, one can envision creating shell-like structures, where layers of polymers alternate with layers of inorganic species.

To achieve such synthetic capabilities, it is critically important to understand how the presence of the particles affects the ordering of the block copolymers and in turn, how the microphase separation of the chains affects the behavior of the fillers. Developing such an understanding is complicated by the fact that the number of parameters controlling the behavior of the system is large; the observed microstructures will clearly depend on the size, shape, and volume fraction of particles, the composition of the copolymers, and the interaction energies between the different species. As

\footnotetext{
† University of Pittsburgh.

‡ Present address: The Dow Chemical Company, 1702 Building, Midland, Michigan 48674

$\S$ University of Reading.
}

yet, systematic experimental studies to determine the factors that govern the bulk morphology of copolymer/ particle mixtures have not been undertaken. However, experimental investigations into the properties of thin films of diblocks and nanoparticles ${ }^{9-19}$ have revealed novel nanostructured films with alternating regions of polymer-rich and particle-rich domains.

Theoretical investigations into the factors that control the kinetics or thermodynamics of block copolymer/ particle composites have been relatively limited. Dynamical density functional theory 20 has been used to investigate the structural evolution of a diblock melt in the presence of a few macroscopic filler particles. A hybrid cell dynamical system method ${ }^{21,22}$ has provided insight into the dynamic behavior of diblock/nanoparticle systems. Recently, Huh et al ${ }^{23}$ used Monte Carlo simulations and scaling theory in the strong segregation limit to predict the morphology and phase diagram for a bulk diblock/nanosphere system. Additional theoretical models would be particularly useful for predicting the mesophases of copolymer/nanoparticle mixtures and thus, providing guidelines for engineering the desired nanocomposite morphologies without expending considerable synthetic effort.

In this article, we describe a theory for determining the equilibrium or metastable morphologies for mixtures of diblock copolymer melts and solid, spherical nanoparticles. ${ }^{24}$ We recently combined a self-consistent field theory (SCFT) for diblocks with a weighted-density approximation (WDA) of a density functional theory (DFT) for particles to determine the distribution of particles within lamellar morphologies. ${ }^{24}$ SCFT has proven to be a powerful method for calculating equilibrium morphologies in pure polymeric systems. ${ }^{25}$ There are two features of the SCFT that are particularly advantageous in these studies. First, we can choose to use a combinatorial screening method of solution that 
does not require a priori assumptions about the structure of the system; thus, we can detect previously unobserved morphologies. Second, SCFT can be extended in a straightforward way to more complicated copolymer architectures (e.g., multiblock and comb) or to include homopol ymers or sol vents. We also note that the DFT model ${ }^{26}$ used in our calculations can be adapted for use with other shapes of nanofillers, not just spheres. ${ }^{27}$ Thus the combined SCFT/DFT approach yields a general method for studying the equilibrium properties of a broad class of nanocomposite systems.

In this paper, we provide a complete description of our SCFT/DFT theory and not only focus on the lamellar case (see ref 24) but also explore morphologies that show chemical variation in more than one dimension. In the following, section 2 contains the description of our model, the results and discussion are given in section 3 , and section 4 contains conclusions.

\section{Theory}

We consider a system of $n_{d} A B$ diblock copolymers together with $n_{p}$ hard spherical particles of chemical species $\mathrm{P}$. If each copolymer $\alpha$ is parametrized al ong a space curve $\mathbf{r}_{\alpha}(\mathrm{s})$ with a variable $\mathrm{s}$ that runs from 0 to 1 , then the partition function for the system can be written as

$$
\begin{array}{r}
\mathbf{Z}=\frac{1}{\mathrm{n}_{\mathrm{p}} ! \mathrm{n}_{\mathrm{d}} !} \int \prod_{\alpha=1}^{\mathrm{n}_{\mathrm{d}}} \tilde{\mathscr{D}} \mathbf{r}_{\alpha} \prod_{\beta=1}^{\mathrm{n}_{\mathrm{p}}} \mathrm{d} \mathbf{R}_{\beta} \delta\left[1-\hat{\varphi}_{\mathrm{A}}(\mathbf{r})-\hat{\varphi}_{\mathrm{B}}(\mathbf{r})-\right. \\
\left.\hat{\varphi}_{\mathrm{P}}(\mathbf{r})\right] \exp \left\{-\rho_{0} \int \mathrm{d} \mathbf{r}\left[\chi_{\mathrm{AB}} \hat{\varphi}_{\mathrm{A}}(\mathbf{r}) \hat{\varphi}_{\mathrm{B}}(\mathbf{r})+\chi_{\mathrm{AP}} \hat{\varphi}_{\mathrm{A}}(\mathbf{r}) \hat{\varphi}_{\mathrm{P}}(\mathbf{r})+\right.\right. \\
\left.\left.\chi_{\mathrm{BP}} \hat{\varphi}_{\mathrm{B}}(\mathbf{r}) \hat{\varphi}_{\mathrm{P}}(\mathbf{r})\right]\right\}
\end{array}
$$

where the $\delta$ function enforces incompressibility, and

$$
\tilde{\mathscr{D}} \mathbf{r}_{\alpha} \equiv \mathscr{D} \mathbf{r}_{\alpha} \mathrm{P}\left[\mathbf{r}_{\alpha} ; 0,1\right]
$$

with

$$
P\left[\mathbf{r}_{\alpha} ; s_{1}, s_{2}\right] \propto \exp \left\{-\frac{3}{2 \mathrm{Na}^{2}} \int_{s_{1}}^{s_{2}} d s\left|\frac{d \mathbf{r}_{\alpha}(s)}{d s}\right|^{2}\right\}
$$

This weighting factor incorporates the Gaussian nature of the chains, where $a$ is the statistical segment length (assumed the same for all segments), and $\mathrm{N}$ is the number of segments of volume $\rho_{0}{ }^{-1}$ in the chain. The $\chi_{i j}$ $(i, j=A, B, P)$ are the Flory-Huggins interaction parameters between the various chemical species. The concentration operators for this system are given by

$$
\begin{gathered}
\hat{\varphi}_{A}(\mathbf{r})=\frac{\mathrm{N}}{\rho_{0}} \sum_{\alpha=1}^{\mathrm{n}_{\mathrm{d}}} \int_{0}^{\mathrm{f}} \mathrm{ds} \delta\left(\mathbf{r}-\mathbf{r}_{\alpha}(\mathrm{s})\right) \\
\hat{\varphi}_{\mathrm{B}}(\mathbf{r})=\frac{\mathrm{N}}{\rho_{0}} \sum_{\alpha=1}^{\mathrm{n}_{\mathrm{d}}} \int_{\mathrm{f}}^{1} \mathrm{ds} \delta\left(\mathbf{r}-\mathbf{r}_{\alpha}(\mathrm{s})\right) \\
\hat{\varphi}_{\mathrm{P}}(\mathbf{r})=\frac{\alpha}{\mathrm{V}_{\mathrm{R}}} \int_{\left|\mathbf{r}^{\prime}\right|<\mathrm{R}} \mathrm{d} \mathbf{r}^{\prime} \hat{\rho}_{\mathrm{P}}\left(\mathbf{r}+\mathbf{r}^{\prime}\right) \\
\hat{\rho}_{\mathrm{P}}(\mathbf{r})=\frac{\mathrm{N}}{\rho_{0}} \sum^{\mathrm{n}_{\mathrm{P}}} \delta\left(\mathbf{r}-\mathbf{R}_{\alpha}\right)
\end{gathered}
$$

where $\mathrm{R}$ is the radius of each spherical particle, $\mathbf{R}_{\alpha}$ is the position of the center of the $\alpha$ th particle, and $f$ is the fraction of the diblock that is of the A chemical species. F urthermore, $\mathrm{v}_{\mathrm{R}}$ is the vol ume of one spherical particle

$$
V_{R} \equiv \frac{4 \pi R^{3}}{3}
$$

and $\alpha$ is the ratio of the sphere to diblock volumes

$$
\alpha \equiv \frac{\mathrm{V}_{\mathrm{R}} \rho_{0}}{\mathrm{~N}}=\frac{4 \pi}{3}\left(\frac{\mathrm{R}}{\mathrm{R}_{0}}\right)^{3} \overline{\mathrm{N}}^{1 / 2}
$$

where $\mathrm{R}_{0} \equiv \mathrm{aN}^{1 / 2}$ is the natural size of the polymer, and $\overline{\mathrm{N}} \equiv \mathrm{a}^{6} \rho_{0}{ }^{2} \mathrm{~N}$ is the invariant polymerization index. The operator $\hat{\rho}_{\mathrm{p}}(\mathbf{r})$ is the spherical particle center distribution. All four of these quantities (concentration operators in eqs $2-5$ ) are dimensionless.

The partition function in eq 1 can be rewritten using functions instead of operators by following the procedure outlined in ref 28 . The result is

$$
\begin{array}{r}
\mathrm{Z}=\int \mathscr{D} \Phi_{\mathrm{A}} \mathscr{D} \Phi_{\mathrm{B}} \mathscr{D} \rho_{\mathrm{P}} \mathscr{D} \mathrm{W}_{\mathrm{A}} \mathscr{D} \mathrm{W}_{\mathrm{B}} \mathscr{D} \mathrm{W}_{\mathrm{P}} \mathscr{D} \Xi \frac{\mathrm{Q}_{\mathrm{p}}{ }^{{ }_{\mathrm{P}}} \mathrm{Q}_{\mathrm{d}}{ }_{\mathrm{n}_{\mathrm{d}}}}{\mathrm{n}_{\mathrm{p}} ! \mathrm{n}_{\mathrm{d}} !} \times \\
\exp \left\{-\frac{\rho_{0}}{\mathrm{~N}} \int \mathrm{d} \mathbf{r}\left[\chi_{\mathrm{AB}} \mathrm{N} \Phi_{\mathrm{A}} \Phi_{\mathrm{B}}+\chi_{\mathrm{AP}} \mathrm{N} \Phi_{\mathrm{A}} \Phi_{\mathrm{P}}+\right.\right. \\
\chi_{\mathrm{B} P} \mathrm{~N} \Phi_{\mathrm{B}} \Phi_{\mathrm{P}}-\mathrm{W}_{\mathrm{A}} \Phi_{\mathrm{A}}-\mathrm{W}_{\mathrm{B}} \Phi_{\mathrm{B}}-\mathrm{W}_{\mathrm{P}} \rho_{\mathrm{P}}-\Xi\left(1-\Phi_{\mathrm{A}}-\right. \\
\left.\left.\left.\Phi_{\mathrm{B}}-\Phi_{\mathrm{P}}\right)\right]\right\}
\end{array}
$$

where

$$
\mathrm{Q}_{\mathrm{d}}=\int \tilde{\mathscr{D}} \mathbf{r}(\mathrm{s}) \exp \left[-\int_{0}^{\mathrm{f}} \mathrm{ds} \mathrm{W}_{\mathrm{A}}(\mathbf{r}(\mathrm{s}))-\int_{\mathrm{f}}^{1} \mathrm{ds} \mathrm{W}_{\mathrm{B}}(\mathbf{r}(\mathrm{s}))\right]
$$

$$
\mathrm{Q}_{\mathrm{p}}=\int \mathrm{d} \mathbf{r} \exp \left[-\mathrm{W}_{\mathrm{p}}(\mathbf{r})\right]
$$

The mean field approximation in eq 8 gives a free energy of

$$
\begin{gathered}
\frac{\mathrm{NF}}{\rho_{0} \mathrm{k}_{\mathrm{B}} T \mathrm{~V}}=-\frac{\phi_{\mathrm{P}}}{\alpha} \ln \left(\frac{\mathrm{Q}_{\mathrm{p}} \alpha}{\mathrm{V} \phi_{\mathrm{P}}}\right)-\left(1-\phi_{\mathrm{P}}\right) \ln \left[\frac{\mathrm{Q}_{\mathrm{d}}}{\mathrm{V}\left(1-\phi_{\mathrm{P}}\right)}\right]+ \\
\frac{1}{\mathrm{~V}} \int \mathrm{d} \mathbf{r}\left[\chi_{\mathrm{AB}} \mathrm{N} \varphi_{\mathrm{A}} \varphi_{\mathrm{B}}+\chi_{\mathrm{AP}} \mathrm{N} \varphi_{\mathrm{A}} \varphi_{\mathrm{P}}+\chi_{\mathrm{BP}} \mathrm{N} \varphi_{\mathrm{B}} \varphi_{\mathrm{P}}-\right. \\
\left.\mathrm{w}_{\mathrm{A}} \varphi_{\mathrm{A}}-\mathrm{w}_{\mathrm{B}} \varphi_{\mathrm{B}}-\mathrm{w}_{\mathrm{P}} \rho_{\mathrm{P}}-\xi\left(1-\varphi_{\mathrm{A}}-\varphi_{\mathrm{B}}-\varphi_{\mathrm{P}}\right)\right]
\end{gathered}
$$

where $\phi_{\mathrm{P}}$ is the overall volume fraction of particles in the composite, Vis the volume of the system, $\mathrm{T}$ is the temperature and $k_{B}$ is Boltzmann's constant. We see in eq 11 that we have now introduced the fields $w_{A}(\mathbf{r}), W_{B}-$ $(\mathbf{r})$, and $w_{P}(\mathbf{r})$, which act on segments of the $A$ and $B$ polymer chains and the $P$ particles, respectively. These take the place of the many-body interactions in the system.

Before defining the rest of the terms in eq 11 , it needs to be pointed out that the free energy is incompl ete. The application of the mean field approximation means that exact incompressibility is now replaced by an ensemble average incompressibility, which does not take into accout excluded volume interactions between the spherical particles. To properly account for the excluded volume interaction, we add the nonideal steric term calculated using the Tarazona ${ }^{26}$ density functional theory to the free energy in eq 11 . The Tarazona DFT is based on the Carnahan-Starling ${ }^{29}$ equation of state for a hard sphere fluid, modified (by means of the so- 
called weighted density approximation) so that the model can describe both homogeneous (liquid) and inhomogeneous (crystal line) morphologies. The addition of such a steric term follows the example of Matsen and Barrett, ${ }^{30}$ who used a similar approach to study rodcoil block copolymers. The free energy is now written as

$$
\begin{array}{r}
\frac{\mathrm{NF}}{\rho_{0} \mathrm{k}_{\mathrm{B}} \mathrm{TV}}=-\frac{\phi_{\mathrm{P}}}{\alpha} \ln \left(\frac{\mathrm{Q}_{\mathrm{p}} \alpha}{\mathrm{V} \phi_{\mathrm{P}}}\right)-\left(1-\phi_{\mathrm{P}}\right) \ln \left[\frac{\mathrm{Q}_{\mathrm{d}}}{\mathrm{V}\left(1-\phi_{\mathrm{P}}\right)}\right]+ \\
\frac{1}{\mathrm{~V}} \int \mathrm{d} \boldsymbol{r}\left[\chi_{\mathrm{AB}} \mathrm{N} \varphi_{\mathrm{A}} \varphi_{\mathrm{B}}+\chi_{\mathrm{AP}} \mathrm{N} \varphi_{\mathrm{A}} \varphi_{\mathrm{P}}+\chi_{\mathrm{BP}} \mathrm{N} \varphi_{\mathrm{B}} \varphi_{\mathrm{P}}-\right. \\
\mathrm{W}_{\mathrm{A}} \varphi_{\mathrm{A}}-\mathrm{w}_{\mathrm{B}} \varphi_{\mathrm{B}}-\mathrm{w}_{\mathrm{P}} \rho_{\mathrm{P}}-\xi\left(1-\varphi_{\mathrm{A}}-\varphi_{\mathrm{B}}-\varphi_{\mathrm{P}}\right)+ \\
\left.\rho_{\mathrm{P}} \Psi_{\mathrm{hS}}\left(\bar{\varphi}_{\mathrm{P}}\right)\right]
\end{array}
$$

Here, the hard sphere term $\Psi_{\text {hs }}$ is given by

$$
\Psi_{\mathrm{hs}}(\mathrm{x})=\frac{4 \mathrm{x}-3 \mathrm{x}^{2}}{(1-\mathrm{x})^{2}}
$$

Note that the local volume fraction $\varphi_{\mathrm{p}}$ and the "weighted" nonlocal volume fraction $\bar{\varphi}_{\mathrm{p}}$ are given by

$$
\begin{gathered}
\varphi_{\mathrm{P}}(\mathbf{r})=\frac{\alpha}{\mathrm{V}_{\mathrm{R}}} \int_{\left|\mathbf{r}^{\prime}\right|<\mathrm{R}} \mathrm{d} \mathbf{r}^{\prime} \rho_{\mathrm{P}}\left(\mathbf{r}+\mathbf{r}^{\prime}\right) \\
\bar{\varphi}_{\mathrm{P}}(\mathbf{r})=\frac{\alpha}{\mathrm{v}_{2 \mathrm{R}}} \int_{\left|\mathbf{r}^{\prime}\right|<2 \mathrm{R}} \mathrm{d} \mathbf{r}^{\prime} \rho_{\mathrm{P}}\left(\mathbf{r}+\mathbf{r}^{\prime}\right)
\end{gathered}
$$

where $v_{2 R}$ denotes the volume of a sphere of radius $2 R$.

By varying the free energy in eq 12 , we obtain the mean field equations that describe equilibrium or metastable morphologies. These are

$$
\begin{array}{r}
\mathrm{w}_{\mathrm{A}}(\mathbf{r})=\chi_{\mathrm{AB}} \mathrm{N} \varphi_{\mathrm{B}}(\mathbf{r})+\chi_{\mathrm{AP}} \mathrm{N} \varphi_{\mathrm{P}}(\mathbf{r})+\xi(\mathbf{r}) \\
\mathrm{w}_{\mathrm{B}}(\mathbf{r})=\chi_{\mathrm{AB}} \mathrm{N} \varphi_{\mathrm{A}}(\mathbf{r})+\chi_{\mathrm{BP}} \mathrm{N} \varphi_{\mathrm{P}}(\mathbf{r})+\xi(\mathbf{r}) \\
\mathrm{w}_{\mathrm{P}}(\mathbf{r})=\Psi_{\mathrm{hs}}\left(\bar{\varphi}_{\mathrm{P}}(\mathbf{r})\right)+\frac{\alpha}{\mathrm{v}_{\mathrm{R}}} \int_{\left|\mathbf{r}^{\prime}\right|<\mathrm{R}} \mathrm{d} \mathbf{r}^{\prime}\left[\chi_{\mathrm{AP}} \mathrm{N} \varphi_{\mathrm{A}}\left(\mathbf{r}+\mathbf{r}^{\prime}\right)+\right. \\
\left.\chi_{\mathrm{BP}} \mathrm{N} \varphi_{\mathrm{B}}\left(\mathbf{r}+\mathbf{r}^{\prime}\right)+\xi\left(\mathbf{r}+\mathbf{r}^{\prime}\right)\right]+\frac{\alpha}{\mathrm{v}_{2 \mathrm{R}}} \int_{\left|\mathbf{r}^{\prime}\right|<2 \mathrm{R}} \mathrm{d} \mathbf{r}^{\prime}\left[\rho_{\mathrm{P}}(\mathbf{r}+\right. \\
\left.\left.\mathbf{r}^{\prime}\right) \Psi_{\mathrm{hs}}^{\prime}\left(\bar{\varphi}_{\mathrm{P}}\left(\mathbf{r}+\mathbf{r}^{\prime}\right)\right)\right] \\
\varphi_{\mathrm{A}}(\mathbf{r})=\frac{\left(1-\phi_{\mathrm{P}}\right) \mathrm{V}}{\mathrm{Q}_{\mathrm{d}}} \int_{0}^{\mathrm{f}} \mathrm{ds} \mathrm{q}(\mathbf{r}, \mathrm{s}) \mathrm{q}^{\dagger}(\mathbf{r}, \mathrm{s}) \\
\varphi_{\mathrm{B}}(\mathbf{r})=\frac{\left(1-\phi_{\mathrm{P}}\right) \mathrm{V}}{\mathrm{Q}_{\mathrm{d}}} \int_{\mathrm{f}}^{1} \mathrm{ds} \mathrm{q}(\mathbf{r}, \mathrm{s}) \mathrm{q}^{\dagger}(\mathbf{r}, \mathrm{s}) \\
\rho_{\mathrm{P}}(\mathbf{r})=\frac{\phi_{\mathrm{P}} \mathrm{V}}{\alpha \mathrm{Q}_{\mathrm{p}}} \exp \left[-\mathrm{w}_{\mathrm{P}}(\mathbf{r})\right] \\
\varphi_{\mathrm{A}}(\mathbf{r})+\varphi_{\mathrm{B}}(\mathbf{r})+\varphi_{\mathrm{P}}(\mathbf{r})=1
\end{array}
$$

Here, $\Psi_{\mathrm{hs}}^{\prime}(\mathrm{x})=\mathrm{d} \Psi_{\mathrm{hs}}(\mathrm{x}) / \mathrm{dx}$. The propagators $\mathrm{q}(\mathbf{r}, \mathrm{s})$ and $\mathrm{q}^{\dagger}(\mathbf{r}, \mathrm{s})$ are defined exactly as in ref 28 and are solutions to the modified diffusion equations that are given in that reference. The quantities $Q_{d}$ and $Q_{p}$ can be thought of as the partition functions of single molecules (diblocks or particles) subject to the appropriate fields ( $w_{\mathrm{A}}$ and $\mathrm{W}_{\mathrm{B}}$ for the diblocks and $\mathrm{w}_{\mathrm{P}}$ for the particles). They can now be rewritten as

$$
\begin{aligned}
& \mathrm{Q}_{\mathrm{d}}=\int \mathrm{d} \mathbf{r} \mathrm{q}(\mathbf{r}, \mathrm{s}) \mathrm{q}^{\dagger}(\mathbf{r}, \mathrm{s}) \\
& \mathrm{Q}_{\mathrm{p}}=\int \mathrm{d} \mathbf{r} \exp \left[-\mathrm{w}_{\mathrm{p}}(\mathbf{r})\right]
\end{aligned}
$$

The terms $\varphi_{A}(\mathbf{r})$ and $\varphi_{B}(\mathbf{r})$ are the average local volume fractions of the $A$ and $B$ segments, respectively.

In general, eqs 16-22 must be solved numerically. An exception to this is the uniform phase, where the free energy in eq 12 reduces to

$$
\begin{array}{r}
\frac{\mathrm{NF}}{\rho_{0} \mathrm{k}_{\mathrm{B}} \mathrm{TV}}=\frac{\phi_{\mathrm{P}}}{\alpha} \ln \left(\frac{\phi_{\mathrm{P}}}{\alpha}\right)+\left(1-\phi_{\mathrm{P}}\right) \ln \left(1-\phi_{\mathrm{P}}\right)+ \\
\chi_{\mathrm{AB}} \mathrm{Nf}(1-\mathrm{f})\left(1-\phi_{\mathrm{P}}\right)^{2}+\chi_{\mathrm{AP}} \mathrm{Nf} \phi_{\mathrm{P}}\left(1-\phi_{\mathrm{P}}\right)+ \\
\chi_{\mathrm{BP}} \mathrm{N}(1-\mathrm{f}) \phi_{\mathrm{P}}\left(1-\phi_{\mathrm{P}}\right)+\frac{\phi_{\mathrm{P}}}{\alpha}\left[\frac{4 \phi_{\mathrm{P}}-3 \phi_{\mathrm{P}}{ }^{2}}{\left(1-\phi_{\mathrm{P}}\right)^{2}}\right]
\end{array}
$$

Not all morphologies for the particle/diblock system are known, so we choose to use the real space combinatorial screening algorithm of Drol et and Fredrickson ${ }^{31,32}$ to numerically solve eqs $16-22$. To simplify the system, and the calculation, we assume preferential wetting between the particles and the A block; that is, we take

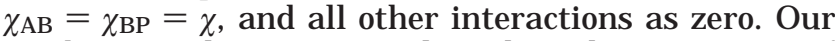
combinatorial screening algorithm then consists of generating the initial values of the fields $\mathrm{w}_{\mathrm{A}}(\mathbf{r})$ and $\mathrm{w}_{\mathrm{B}^{-}}$ (r)(randomly) and using these to calculate the incompressibility field $\xi(\mathbf{r})$ from eqs 16,17 , and 22 . We also assume some initial distribution of particle centers (uniform) that allows us to find $\bar{\varphi}_{\mathrm{P}}(\mathbf{r})$ from eq 15. Next, $\Psi(\mathbf{r})$ and $\Psi^{\prime}(\mathbf{r})$ are found from eq 13 and its derivative respectively, which allows us to use eq 18 to find the particle field $w_{p}(\mathbf{r})$. The propagators $q(\mathbf{r}, \mathrm{s})$ and $\mathrm{q}^{\dagger}(\mathbf{r}, \mathrm{s})$ can be found with the $A$ and $B$ fields, and these together with the particle field allows one to find the single molecule partition functions $\mathrm{Q}_{d}$ and $\mathrm{Q}_{\mathrm{p}}$ from eqs 23 and 24. We then use eqs $19,20,21$, and 14 to find the local density functions, which are then used together with $\xi(\mathbf{r})$ to complete an iteration by updating the $A$ and $B$ fields through eqs 16 and 17. The updated fields (A, B, or $\mathrm{P}$ ) are mixed with the old field values in a superposition such that the algorithm remains stable. ${ }^{32}$ These iterations are continued until incompressibility (eq 22) is satisfied within some acceptable tolerance. The resultant fiel ds, local densities, and $\Psi(\mathbf{r})$ value can then be used in eq 12 to calculate a free energy.

This algorithm is incorporated into a routine that minimizes the free energy with respect to the dimensions of the simulation box. It has been pointed out ${ }^{33}$ that the box size can influence the morphology, and so this minimization is necessary to reduce this effect. Specifically, we choose an initial box size that is sufficiently large to admit any of the various possible morphologies. We then vary this box size through a simplex minimization ${ }^{34}$ to reduce the size effects. Various runs with different initial fields can be examined, and the morphology with the lowest free energy is the stable phase. ${ }^{35}$ Below, we carry out the calculations in two and three dimensions, allowing for chemical variations in more than one direction.

\section{Results and Discussion}

In our previous work, ${ }^{24}$ we examined two systems in the lamellar state. These were the "large" particle case, with $R=0.3 R_{0}$, and the "small" particle case with $R=$ $0.2 R_{0}$. In both cases, we took the invariant polymeriza- 
(a)

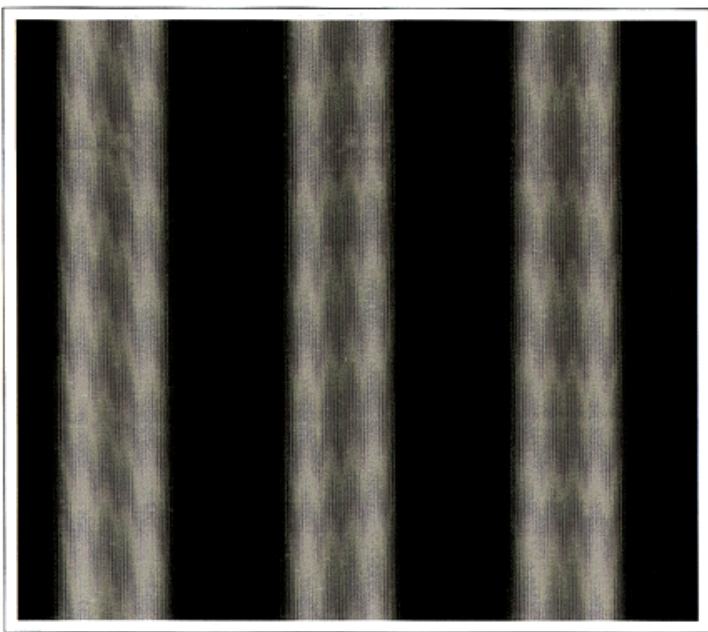

(c)

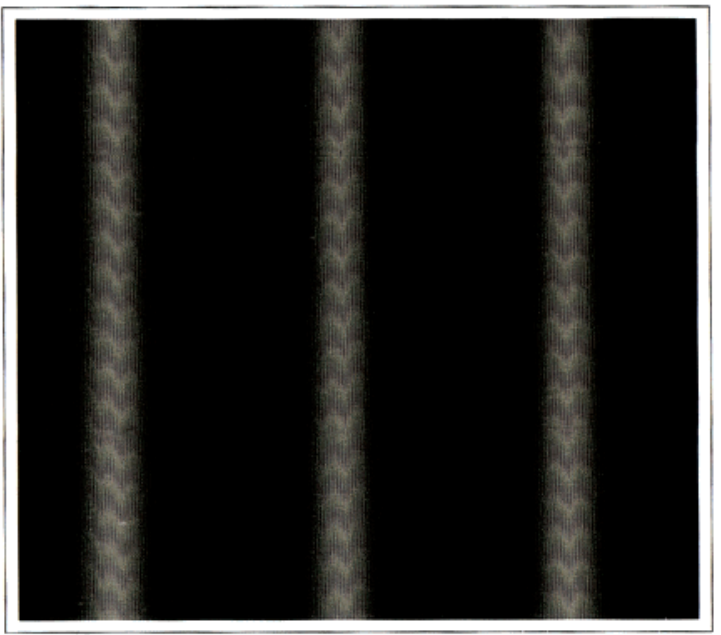

(e)

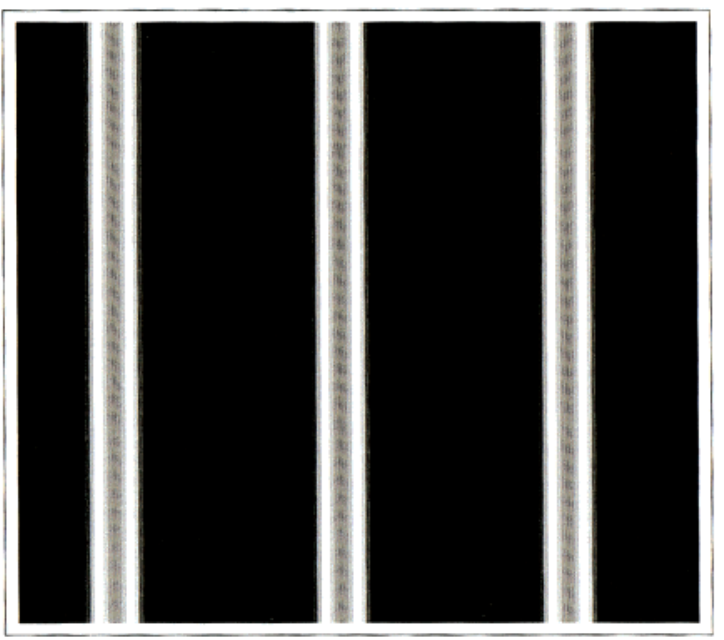

(b)

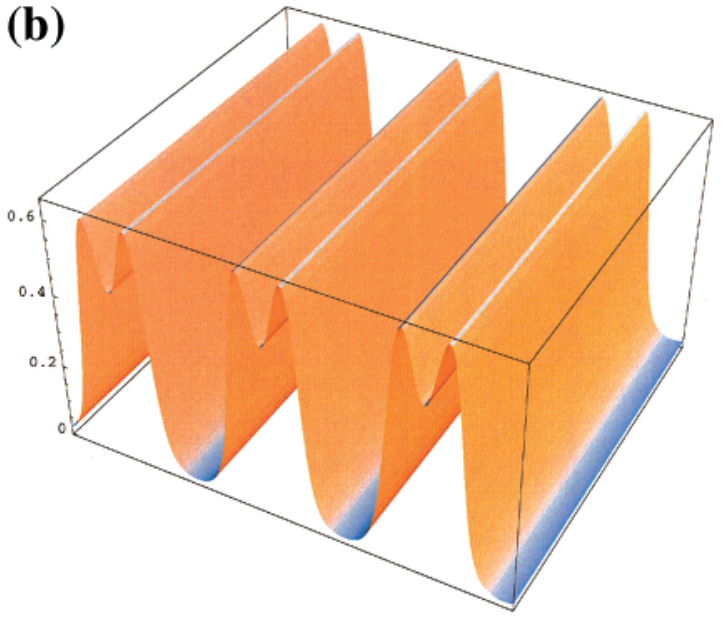

(d)

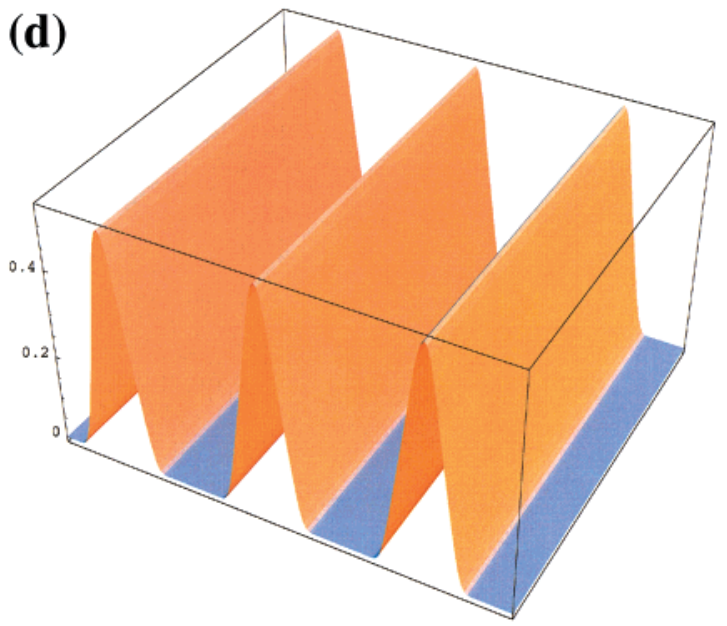

(f)

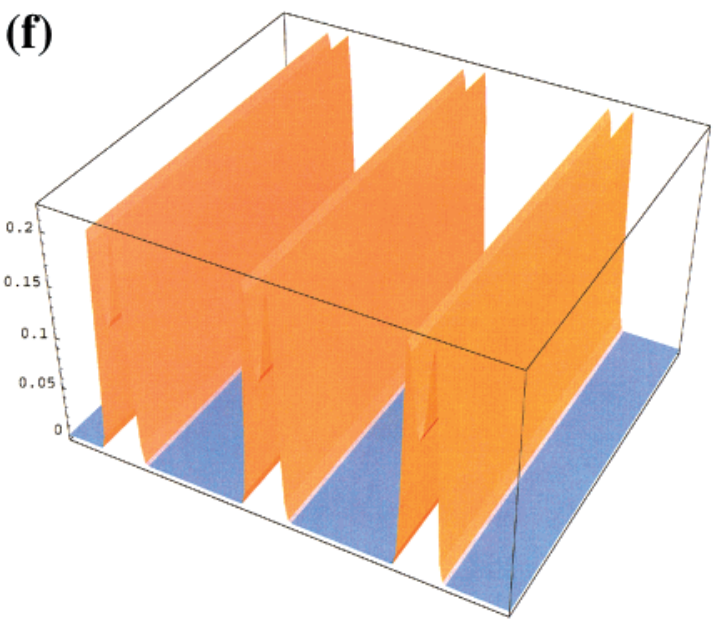

Figure 1. Center-filled lamellar phase for a diblock-particle system. Here, $\mathrm{R}=0.3 \mathrm{R}_{0}, \overline{\mathrm{N}}=1000, \chi \mathrm{N}=20, \phi_{p}=0.15$, and $\mathrm{f}=$ 0.35. Density plots and surface plots are given for the A-block distribution ( $a$ and b), the particle distribution (c and d), and the particle center distribution (e and f). The B-block distribution is not shown. The dimensions of the system are $5.2 R_{0} \times 4.6 R_{0}$. For the density plots, white shows the presence of a species and black the absence.

tion index as $\overline{\mathrm{N}}=1000$, and $\chi \mathrm{N}=20$. In the lamellar case, novel morphologies were seen at a particle volume fraction of $\phi_{\mathrm{p}}=0.15$. To readily compare our new findings with our previous work, we use the same parameters in the current study. The only value we change for the two-dimensional morphologies is the diblock composition parameter $\mathrm{f}$, which we previously took as $f=0.35$. Now, we look outside the lamellar 
(a)

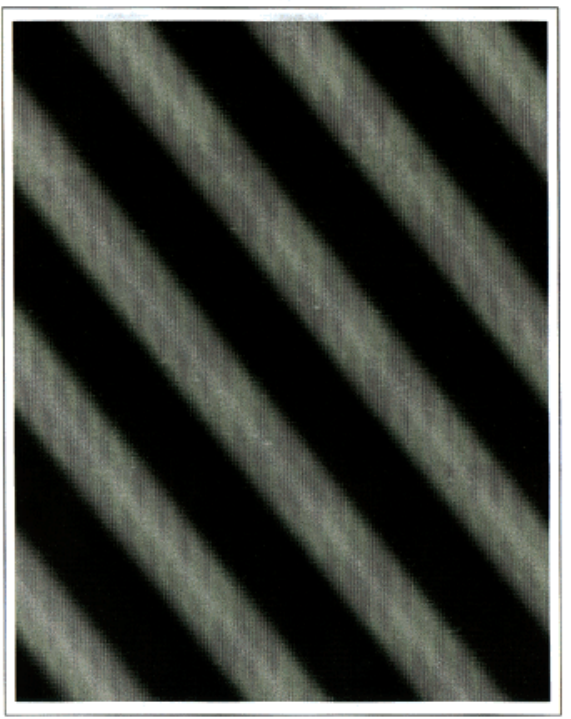

(c)

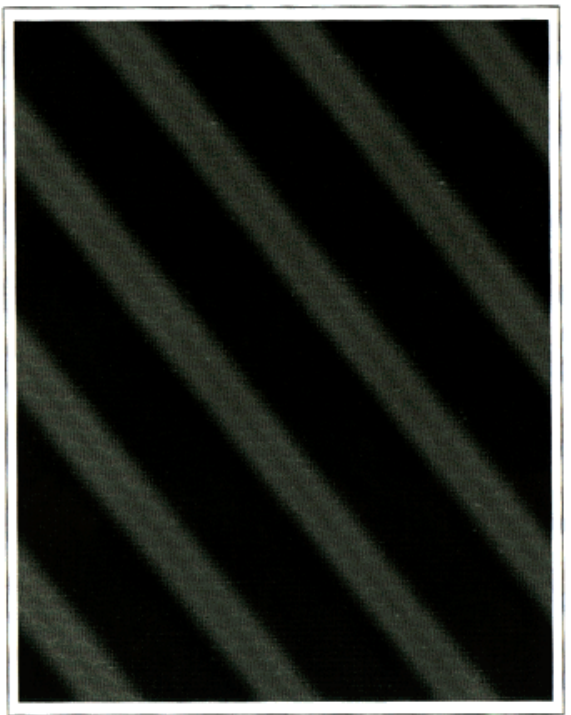

(e)

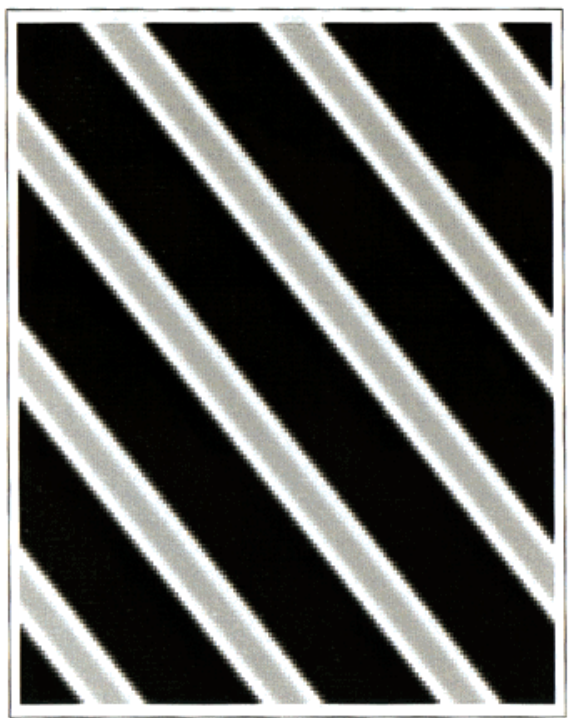

(b)
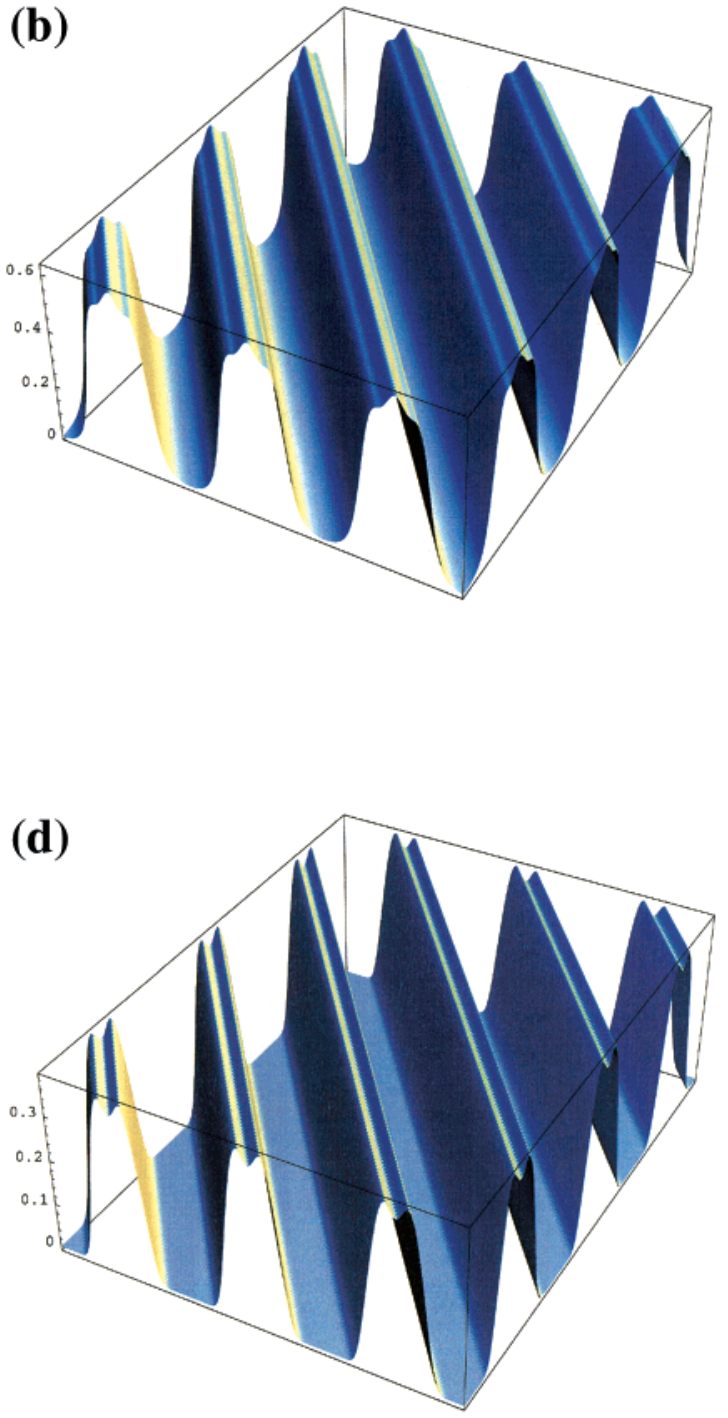

(f)

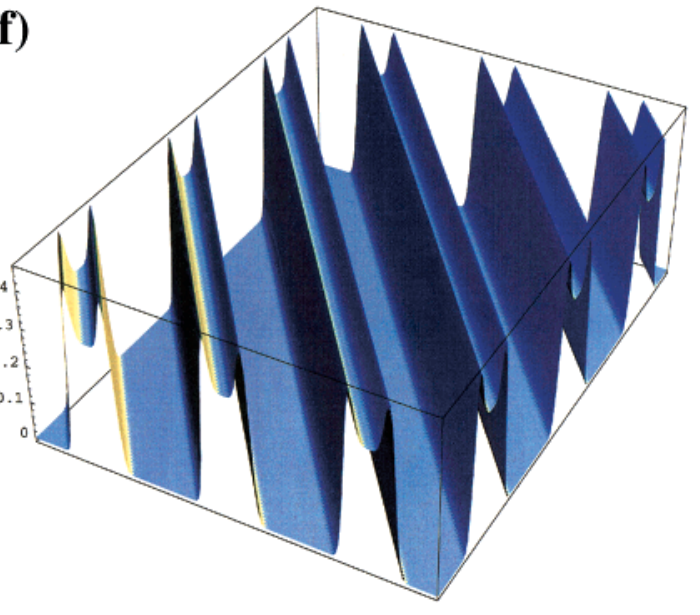

Figure 2. Edge-filled lamellar phase for a diblock-particle system. The same parameters are used as in Figure 1, except now $\mathrm{R}$ $=0.2 \mathrm{R}_{0}$. The dimensions of the system are $6.2 \mathrm{R}_{0} \times 7.9 \mathrm{R}_{0}$. 
(a)

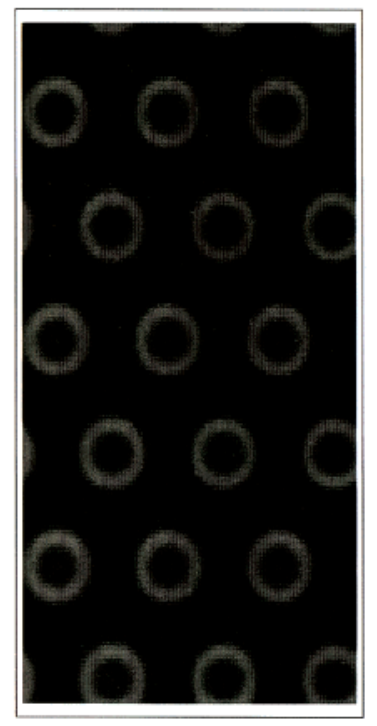

(c)

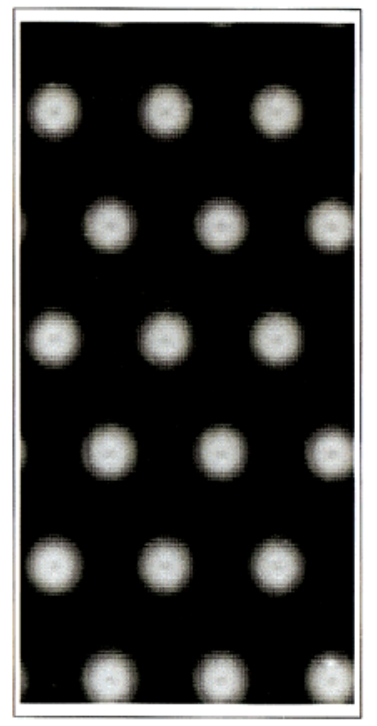

(e)

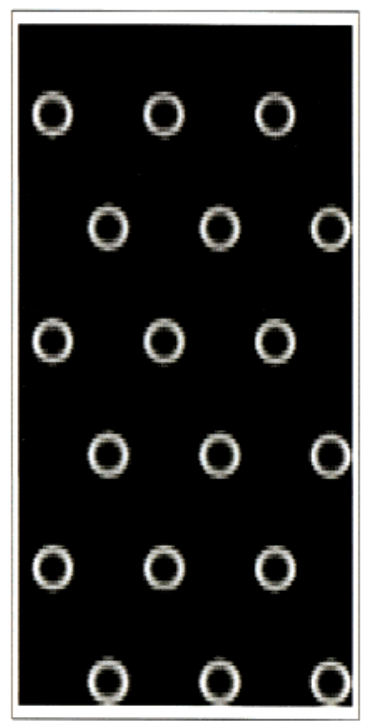

(b)

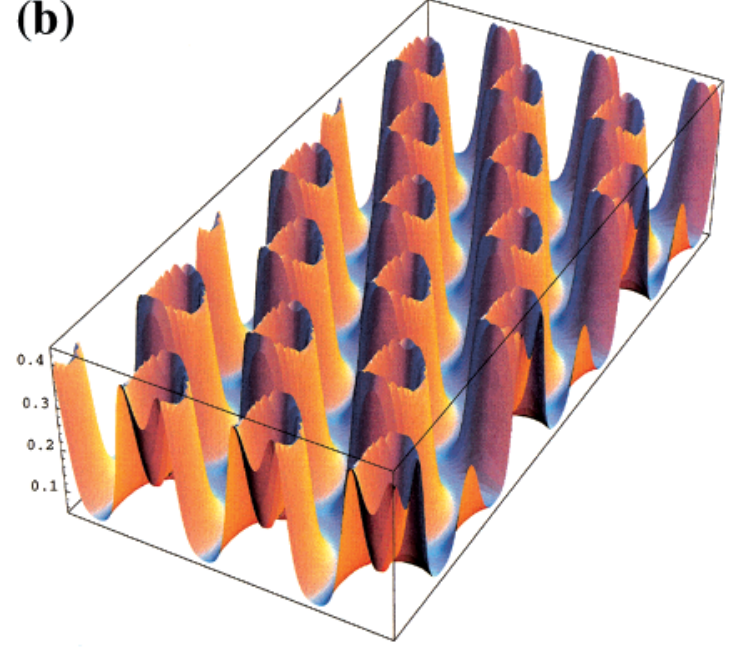

(d)

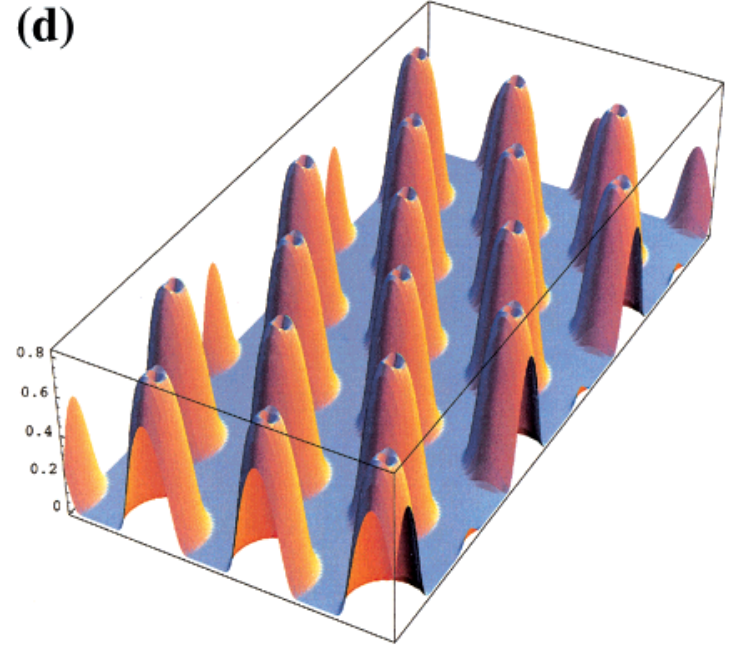

(f)

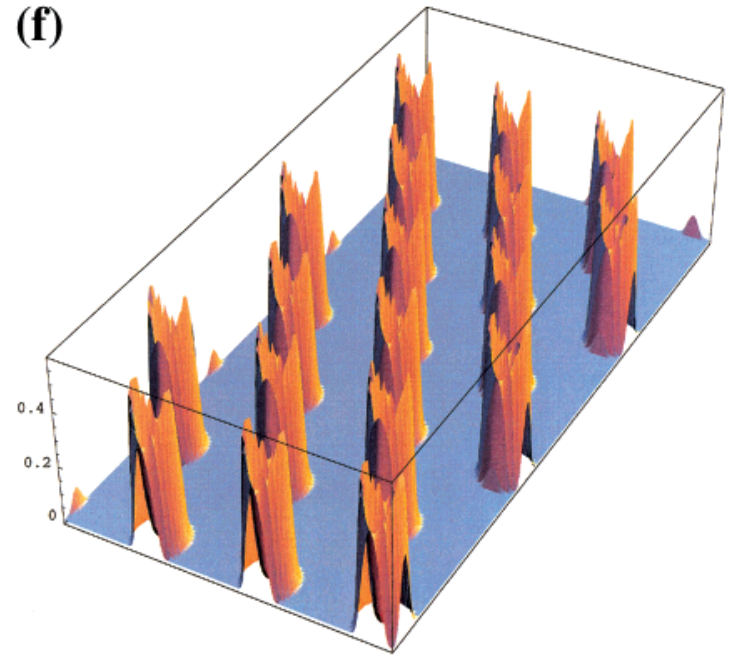

Figure 3. Center-filled cylindrical phase. The same parameters are used as in Figure 1 , but now $f=0.2$. The system dimensions are $5.4 \mathrm{R}_{0} \times 10.9 \mathrm{R}_{0}$ 
(a)

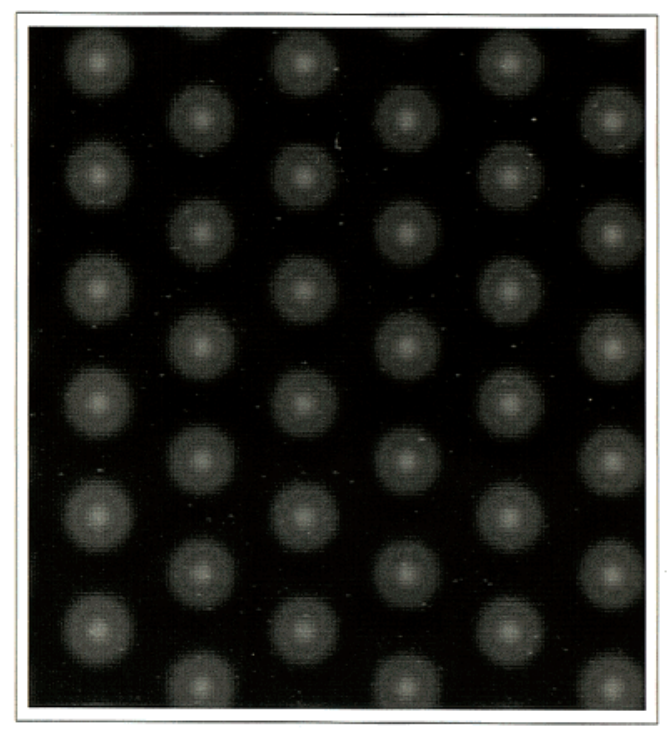

(c)

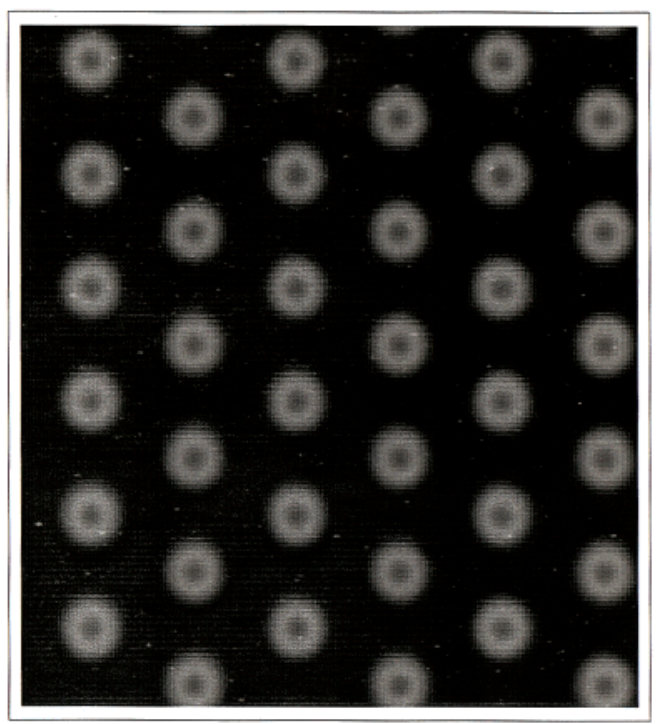

(b)

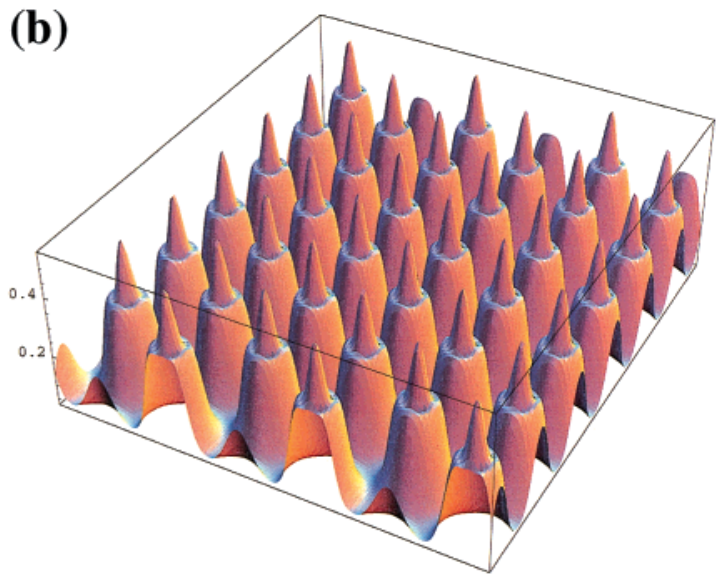

(d)

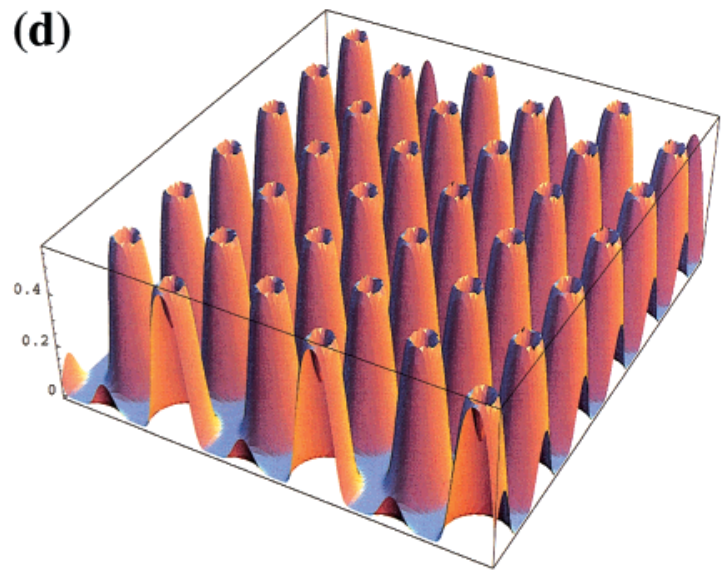

(e)

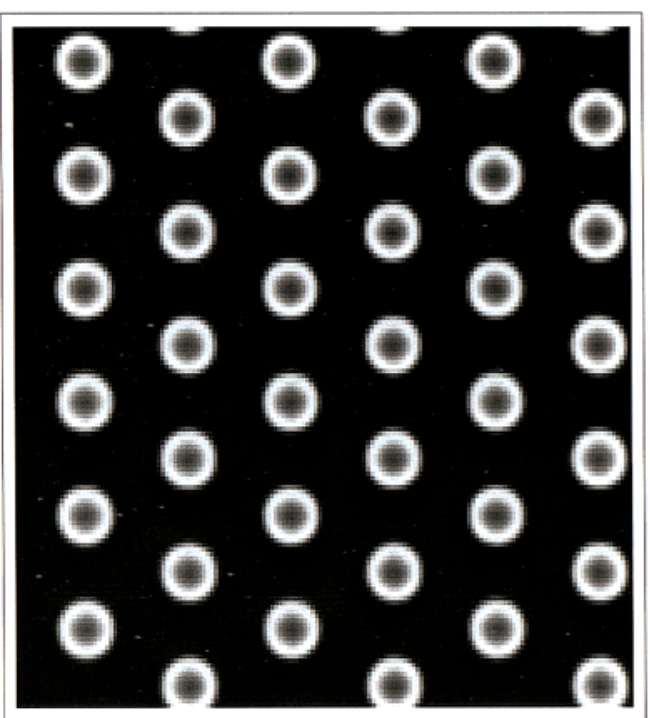

(f)

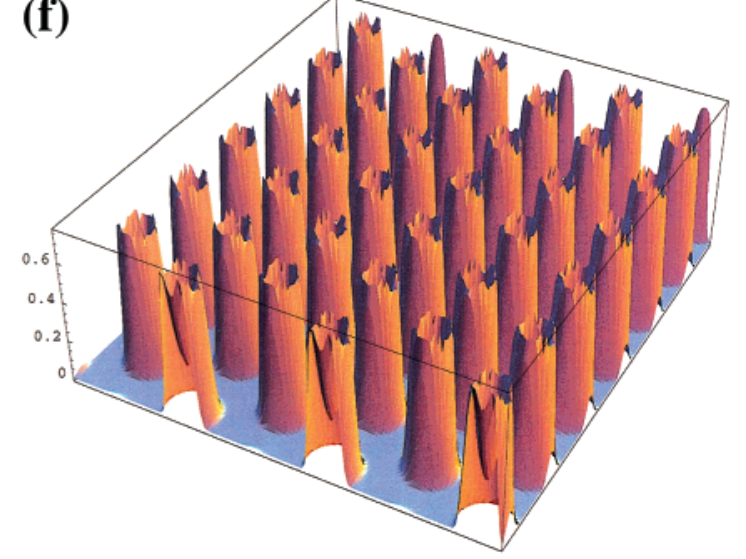

Figure 4. Edge-filled cylindrical phase. The same parameters are used as in Figure 1 , but now $f=0.2$ and $R=0.2 R_{0}$. The system dimensions are $7.6 \mathrm{R}_{0} \times 8.4 \mathrm{R}_{0}$. 

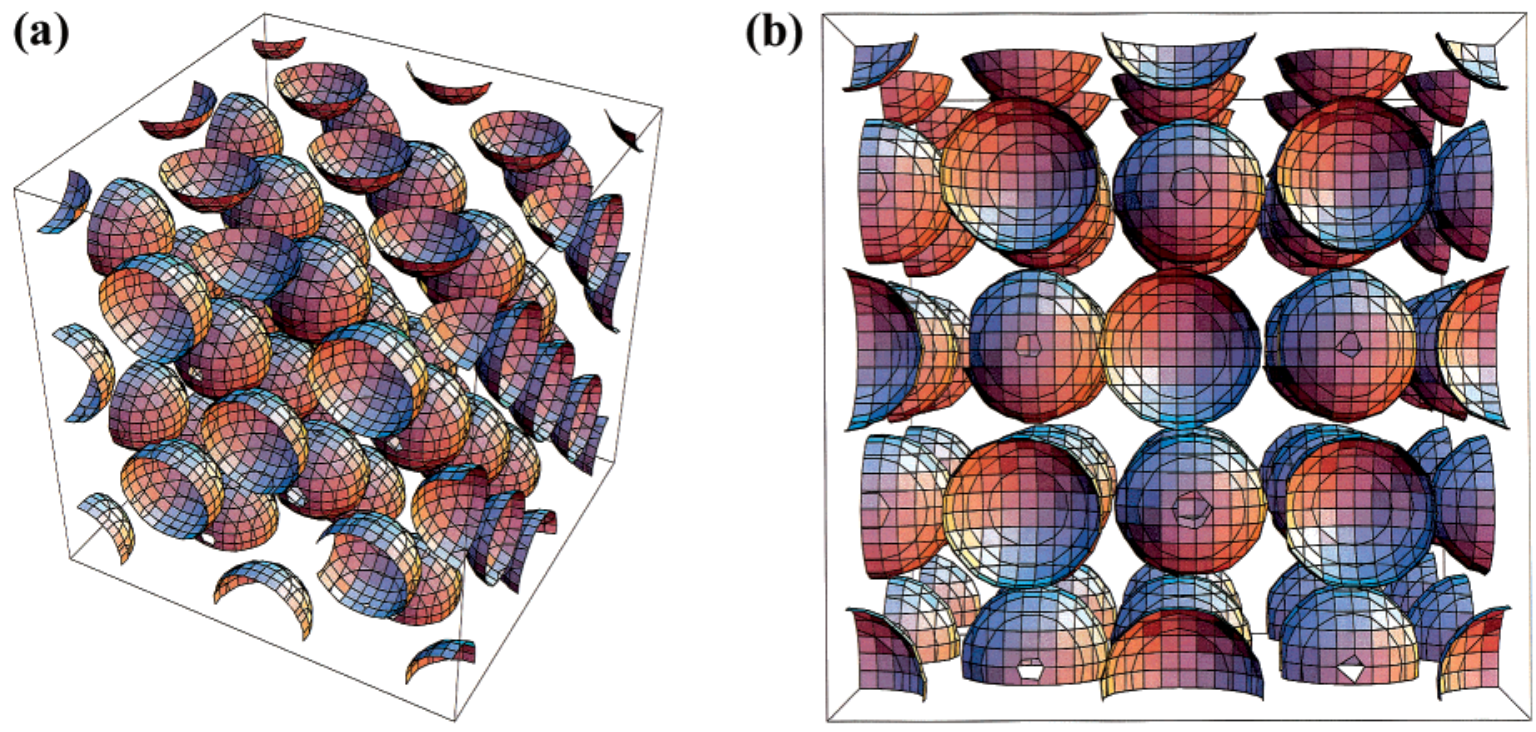

Figure 5. Spherical nanodot phase. The same parameters are used as in Figure 1 , but with $f=0.21, R=0.2 R_{0}$, and $\phi_{p}=0.05$. The isosurface of $\varphi_{\mathrm{p}}(\mathbf{r})=\phi_{\mathrm{p}}=0.05$ is shown for two different angles in panels a and $\mathrm{b}$. The system dimensions are $5.3 \mathrm{R}_{0} \times 3.5 \mathrm{R}_{0}$ $\times 4.9 \mathrm{R}_{0}$.

region, and so we examine the large and small particle cases with diblock compositions of $f=0.2$ and $f=0.6$. For the three-dimensional case, we take $\mathrm{f}=0.21$ and $\phi_{\mathrm{p}}=0.05$.

To facilitate the discussion, we first present the lamellar morphologies found previously with $f=0.35$. Figures 1 and 2 show the large and small particle results, respectively, for a two-dimensional morphology search. In particular, Figure 1 shows the self-assembled lamellar phase where the particles collect in the center of the A-block region and form nanosheets. We will refer to this structure as "center-filled lamellar" (CFL). The CFL phase can easily be recognized by the deficit of $A$ monomers in the middle of the $A$ region, as seen in Figure 1a,b. Figure 2 shows the "edge-filled lamellar" $(E F L)$ morphology where the particles are closer to the edges of the A-phase. The EFL phase is identified by the excess of A monomers in the middle of the A region, as seen in Figure $2 a, b$. These studies indicate that the melt of copolymers can direct the self-assembly of the particles within the compatible A domains and the diblock/nanoparticle mixture can yield hybrid materials with a high degree of spatial organization.

Center-filled and edge-filled morphologies can also be seen if we change the diblock composition to $f=0.2$. Both the large and small particle cases now form hexagonally packed cylinders, ${ }^{36}$ as seen in Figures 3 and 4 , respectively. Parts $a$ and $b$ of Figure 3 reveal $a$ "crater" that shows the partial exclusion of A monomers from the center of the cylinder. This is indicative of the "center-filled cylindrical" (CFC) phase. The stability of a CFC phase has previously been predicted by both scaling theory in the strong segregation limit and Monte Carlo simulations. ${ }^{23}$ Figure $3 \mathrm{~b}$ also shows a small central peak in the middle of the crater. This indicates a slight exclusion of particles from the very center of the core. This probably arises from a staggering of the particle centers (i.e., in a ring shape) as shown in Figure 3 , parts e and f. Overall, the figures clearly indicate that the particles segregate into the core of the cylindrical morphology, forming nanowires through the material. As already mentioned, the center distribution shows that these wires are not straight, but rather twist in perhaps a helical way. ${ }^{37}$ This staggering is consistent with the packing in the self-assembled nanosheets shown in Figure le and $\mathrm{f}$, where the center distribution also indicates a staggered particle configuration.

An edge-filled cylindrical (EFC) morphology is observed in Figure 4 for the small particle case. J ust as in the CFC morphology, the particle center distribution shown in Figure 4e,f has a ring shape. Now, however, there is an excess of A-block in the core of the cylinder rather than a deficit as in the CFC case. This indicates that just as in the EFL situation, the EFC picture has particles nearer the edge of the A-phase.

Nanodots can be formed in addition to nanowires and nanosheets. Figure 5 shows a three-dimensional calculation where the system forms a body centered cubic spherical structure. To realize this morphology, the diblock composition is set to $f=0.21$ while reducing the particle volume fraction to $\phi_{\mathrm{p}}=0.05$. Shown in the figure are two different angles of the particle density isosurface $\varphi_{\mathrm{p}}(\mathbf{r})=\phi_{\mathrm{p}}=0.05$. To better understand this result, a two-dimensional cross-section of the same system is shown in Figure 6 . Once again, the particles self-assemble into the interior of the A-phase. A slight excess of $A$-block can be seen in Figure $6 b$, but since the volume fraction of particles has been reduced, the edge-packing phenomenon is not pronounced.

Different morphologies can be realized if we place the nanoparticles in the majority rather than the minority phase. For $f=0.6$, the large and small particle phases are seen in Figures 7 and 8, respectively. Again, we obtain hexagonally packed cylinders, now however, the particles segregate into the matrix instead of the cylinders, as can be seen in Figures $7 c, d$ and $8 c, d$. If the polymers were to be dissolved from the system, the remaining inorganic components could form a nanoporous material, with a regular arrangement of uniform pores. Similar systems have been fabricated by using a diblock copolymer as a structure directing agent and conventional sol-gel chemistry; ${ }^{38}$ however, the simple mixing of the appropriate diblocks and particles may prove to be a more facile synthetic route. 
(a)

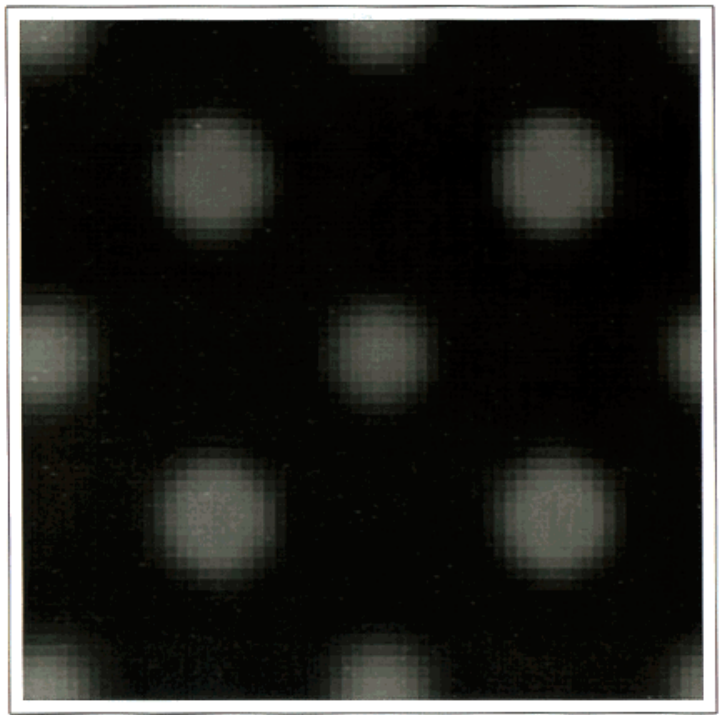

(c)

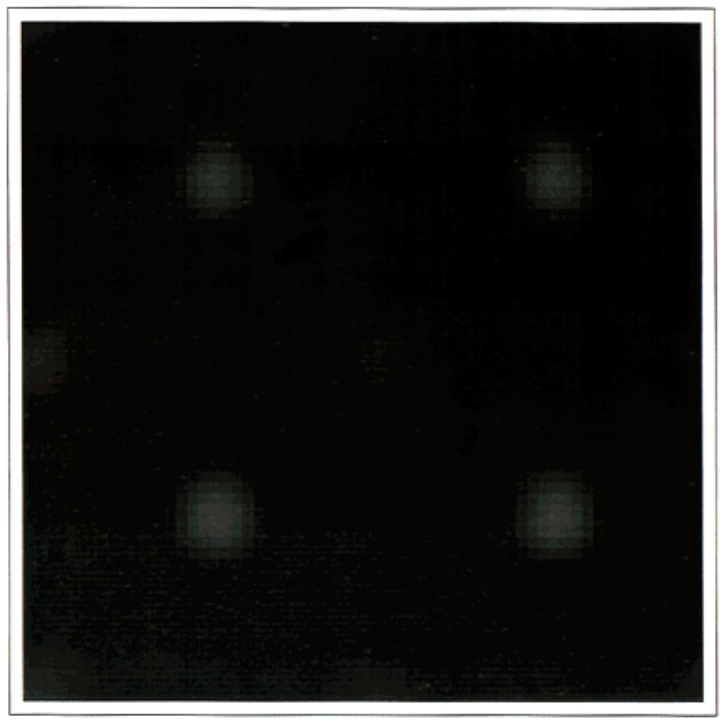

(e)

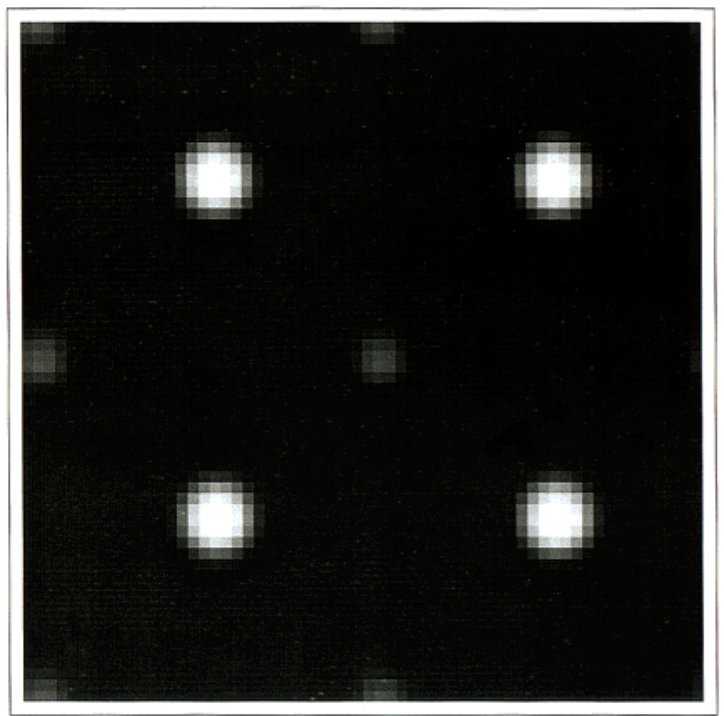

(b)
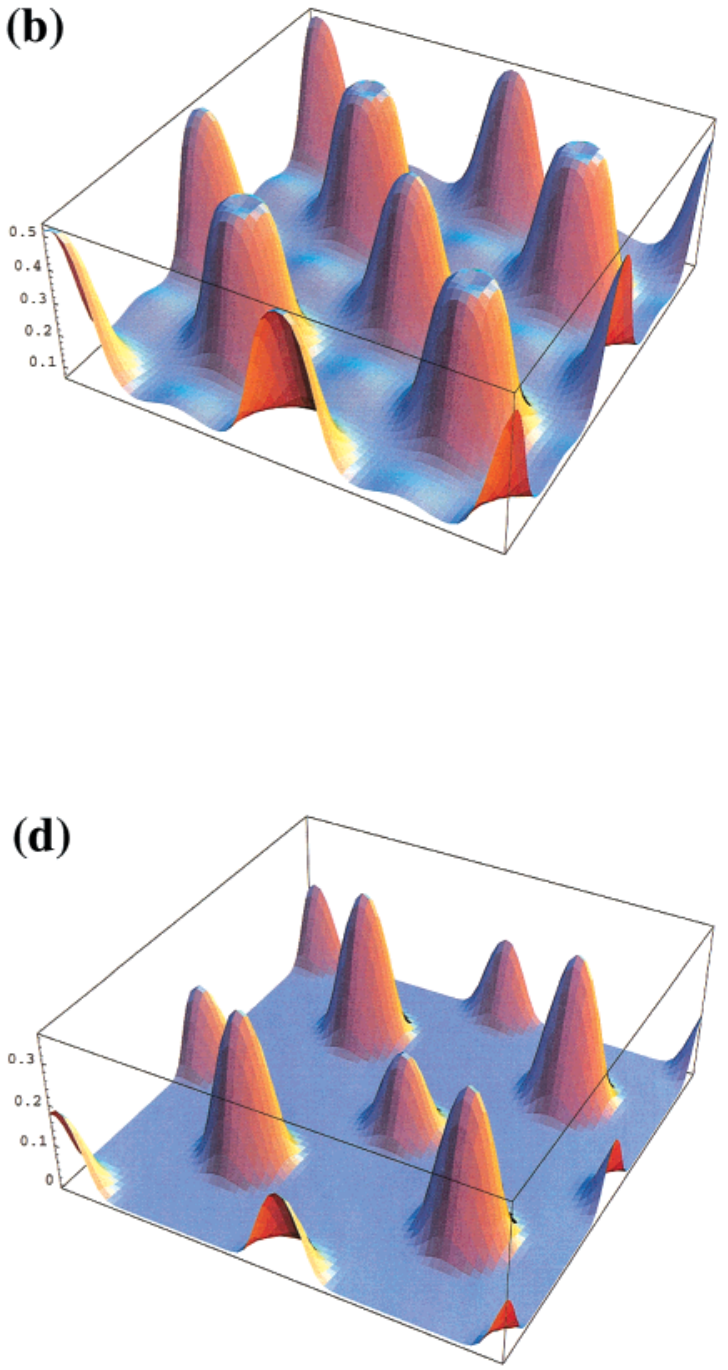

(f)

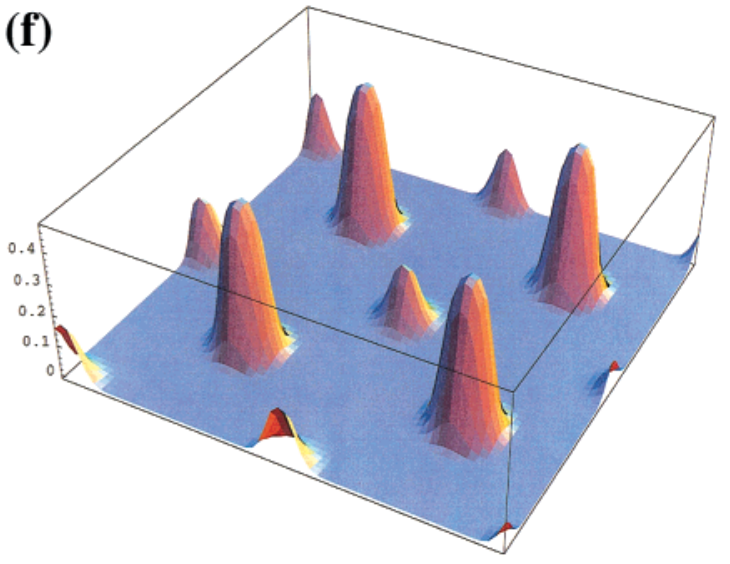

Figure 6. Two-dimensional cross-section of the spherical nanodot phase shown in Figure 5 . The system dimensions are $5.3 R_{0} \times$ $4.9 \mathrm{R}_{0}$. 
(a)

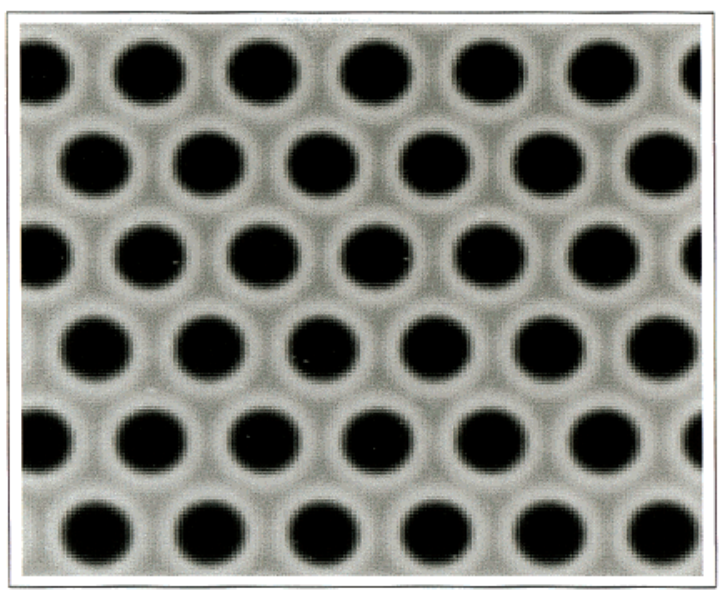

(c)

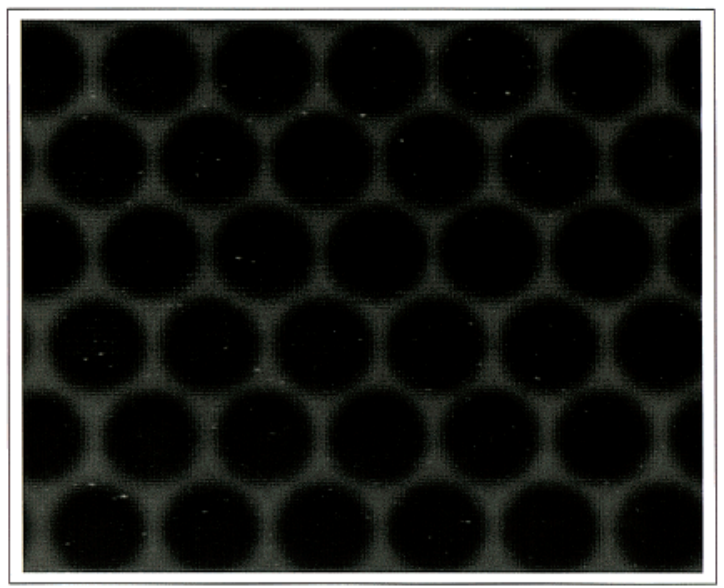

(e)

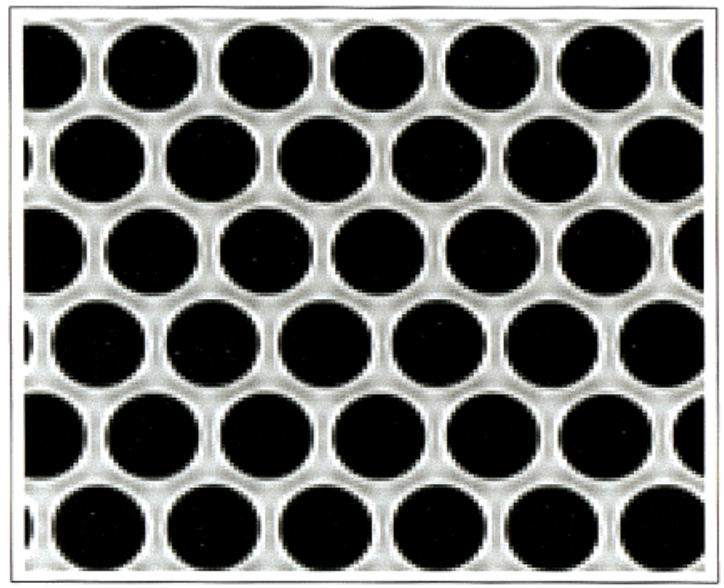

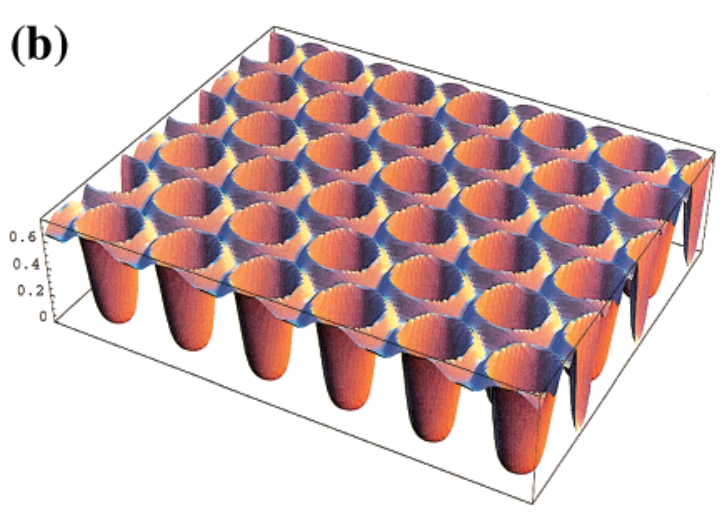

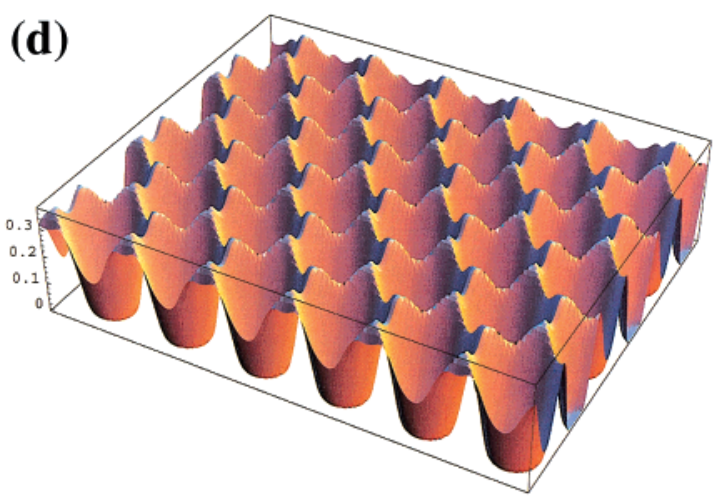

(f)

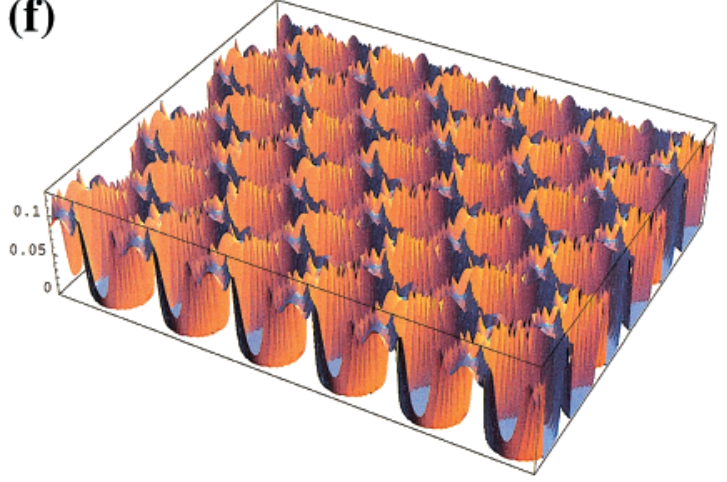

Figure 7. Cylindrical phase with particles in the matrix. The same parameters are used as in Figure 1 , but now $f=0.6$. The system dimensions are $12.4 \mathrm{R}_{0} \times 10.1 \mathrm{R}_{0}$.

The "submorphologies" of the CF or EF are not as apparent in Figures 7 and 8 as in Figures $1-4$. In the latter cases, the A-blocks constitute the minority phase and form extensive brushlike structures. The selfassembly of the particles within these lamellar or cylindrical brushes can be explained from entropic arguments. Specifically, the conformational entropy of the A-blocks surrounding the hard particles is significantly decreased due to the presence of the particle obstructions. If the particles collect together, less surface area is "seen" by the surrounding blocks, and the conformational entropy suffers less, reducing the free energy.23,24 The choice of an CF or EF arrangement comes about purely from the packing considerations of the different-sized particles at a given volume fraction. In the EF case, two particles can fit side-by-side, resulting in an excess of polymer squeezed between the spheres. In the CF case, only one larger particle can fit, resulting in the exclusion of polymer at the position of the particle. It is also packing considerations that cause the staggering effect in the packing in the lamellar cases (see the center distributions, Figures $1 \mathrm{e}, \mathrm{f}$ and $2 \mathrm{e}, \mathrm{f}$ ), and 
(a)

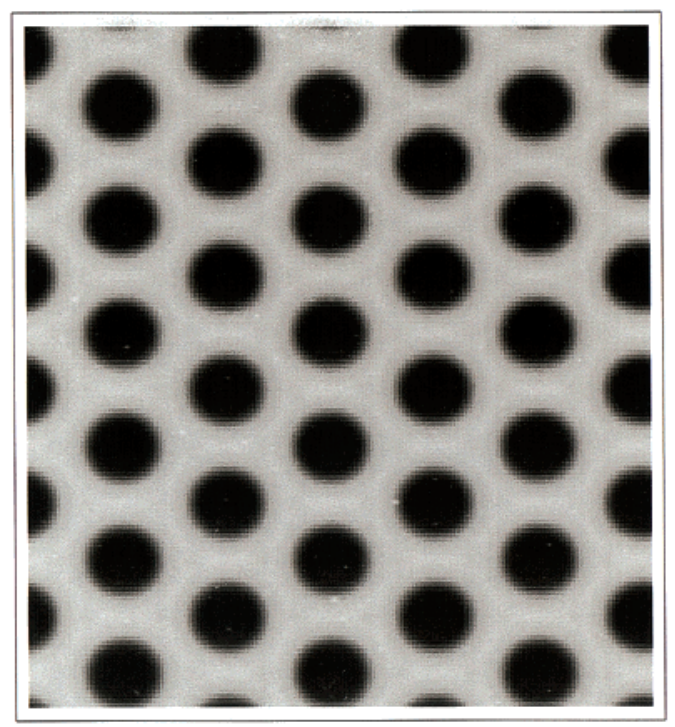

(c)

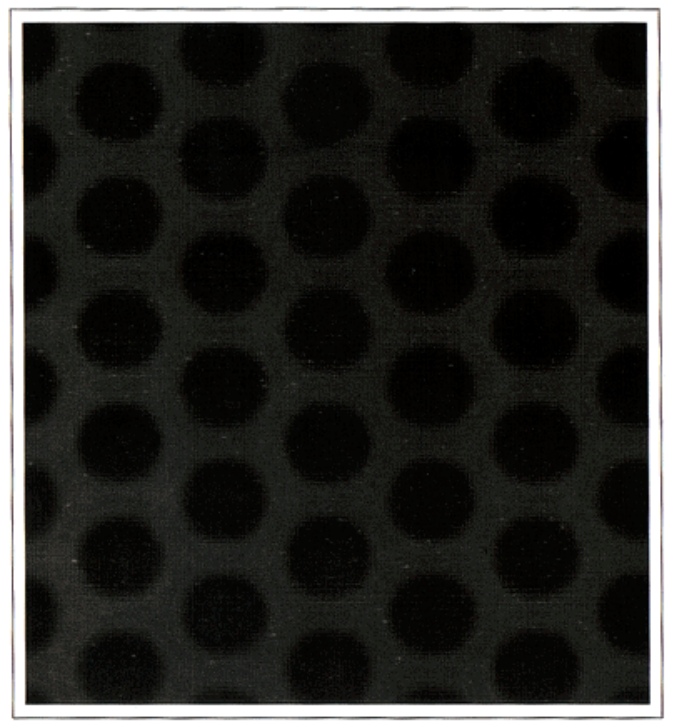

(e)

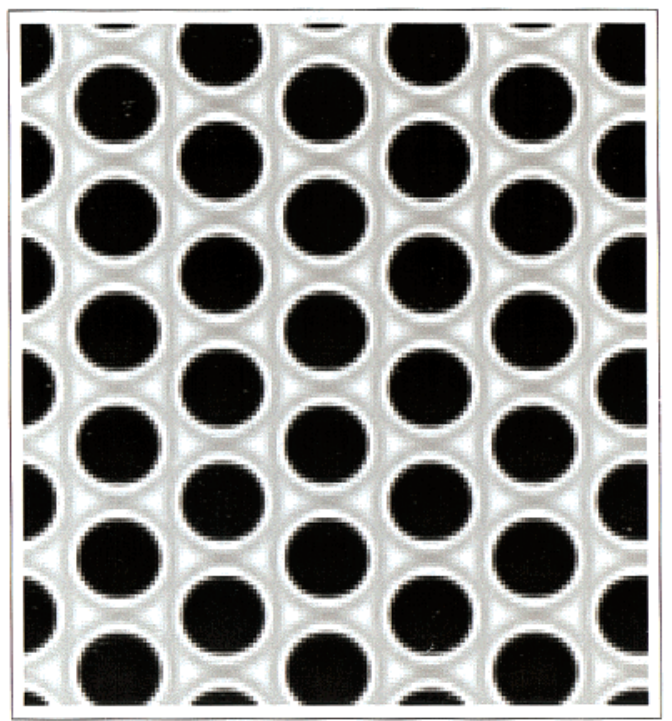

(b)

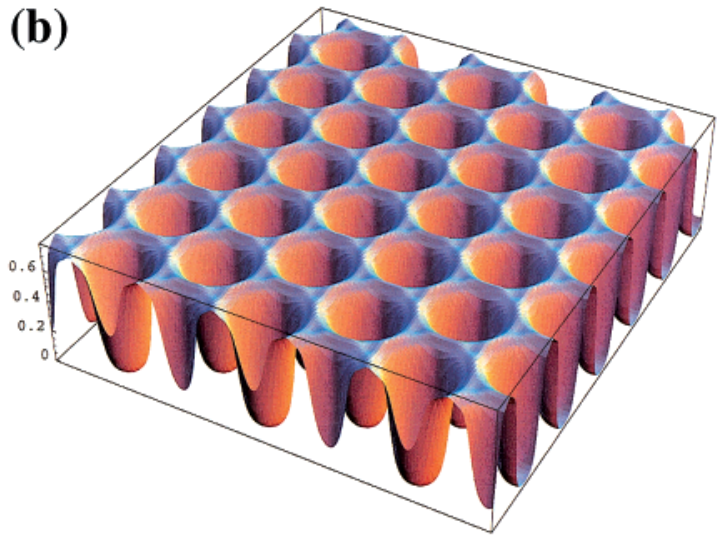

(d)

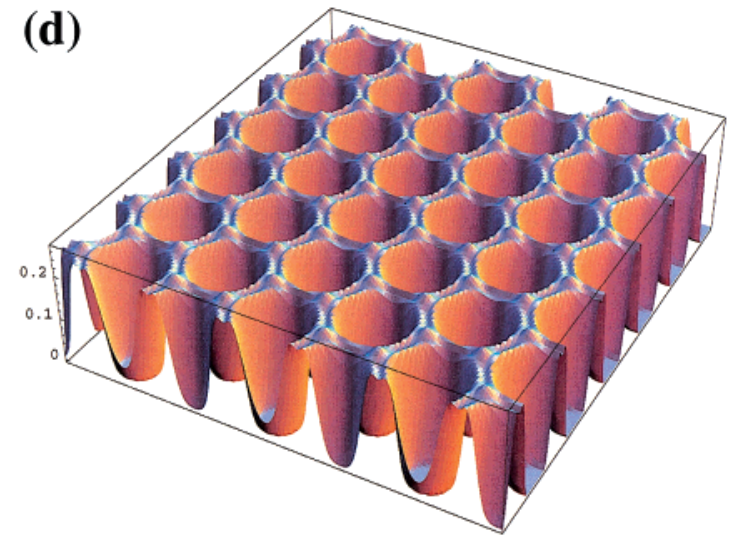

(f)

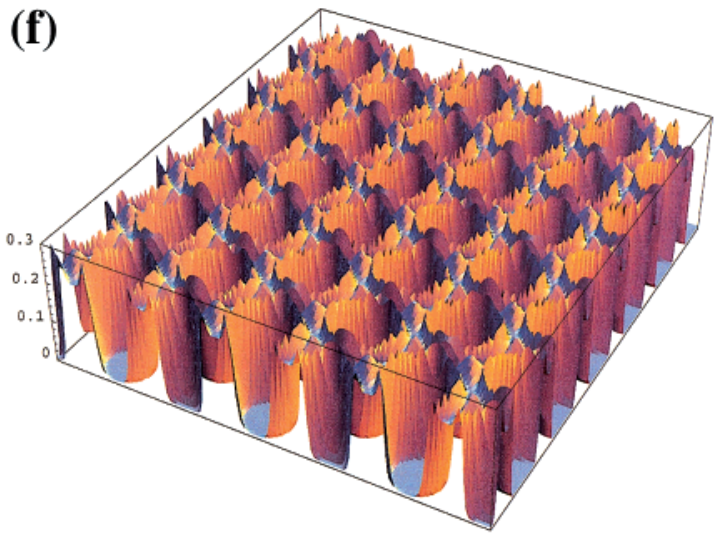

Figure 8. Cylindrical phase with particles in the matrix. The same parameters are used as in Figure 1 , but now $\mathrm{f}=0.6$ and $\mathrm{R}$ $=0.2 R_{0}$. The system dimensions are $10.0 R_{0} \times 10.9 R_{0}$. 
the proposed helical packing in the cylinder cases $^{37}$ (Figures 3 and 4, parts e and f).

\section{Conclusions}

We presented our SCFT/DFT model for predicting the equilibrium phases of mixtures of diblocks and spherical particles. Using this theory, we isolated a variety of one, two-, and three-dimensional morphologies for both large and small particles. If these particles are localized in the minority phase, the fillers can form not only the nanosheets, nanowires and nanodots seen here, but can also assemble into continuous nanoarrays in the hexagonally perforated lamellar or gyroid structures. If, on the other hand, the particles are located in the majority phase of the system, one can create nanoporous materials in a variety of different configurations. One example would be the cylindrical nanoporous material suggested by the images in Figures 7 and 8.

The SCFT/DFT model can be modified to describe particles in the following matrix materials: other copolymer architectures, mixtures of copolymers and homopolymers, homopolymer blends, and polymer/ solvent systems. In addition, the DFT component can be modified to describe nonspherical particles (e.g., rods, platelets, and disks) or mixtures of small and large fillers. Overall, the technique can offer valuable assistance in exploring the rich variety of mesostructures that can occur in polymer-particle mixtures and in designing hybrid materials with the desired morphology.

Acknowledgment. This work was supported by the U.S. Department of Energy, the NSF, the Army Research Office, and the Engineering and Physical Sciences Research Council (U.K.). Extensive use was made of the Center for Molecular and Materials Simulations computing facilites at the University of Pittsburgh.

\section{References and Notes}

(1) Alexandre, M.; Dubois, P. Mater. Sci. Eng. Rev. 2000, 28, 1.

(2) Balazs, A. C. Curr. Opin. Colloid Interface Sci. 2000, 4, 443 and references therein.

(3) Giannelis, E. P. Appl. Organomet. Chem. 1998 12, 675.

(4) Soo, P. P.; Huang, B. Y.; J ang, Y. I.; Chiang, Y. M.; Sadoway, D. R.; Mayes, A. M. J. Electrochem. Soc. 1999, 146, 32.

(5) Templin, M.; Franck, A.; DuChesne, A.; Leist, H.; Zhang, Y. M.; Ulrich, R.; Schadler, V.; Wiesner, U. Science 1997 278, 1795.

(6) Zhao, D.; Feng, J .; Huo, Q.; Melosh, N.; Fredrickson, G. H.; Chmelka, B. F.; Stucky, G. D. Science 1998, 279, 548.

(7) Chan, V. Z. H.; Hoffman, J .; Lee, V. Y.; I atrou, H.; Avgeropoulos, A.; Hadjichristidis, N.; Miller, R. D.; Thomas, E. L. Science 1999, 286, 1716 .

(8) Stupp, S.; Braun, P. V. Science 1997, 277, 1242.

(9) Hamdoun, B.; Ausserre, D.; J oly, S.; Gallot, Y.; Cabuil, V.; Clinard, C. J . Phys. II 1996 6, 493.

(10) Lauter-Pasyuk, V.; Lauter, H. J .; Ausserre, D.; Gallot, Y.; Cabuil, V.; Kornilov, E. I.; Hamdoun, B. Physica B 1998, 241-243, 1092.
(11) Lauter-Pasyuk, V.; Lauter, H. J .; Ausserre, D.; Gallot, Y.; Cabuil, V.; Hamdoun, B.; Kornilov, E. I. Physica B 1998, 248, 243.

(12) Morkved, T. L.; Wiltzius, P.; J aeger, H. M.; Grier, D. G.; Witten, T. A. Appl. Phys. Lett. 1994, 64, 422.

(13) Zehner, R. W.; Lopes, W. A.; Morkved, T. L.; J aeger, H.; Sita, L. R. Langmuir 1998, 14, 241.

(14) Lin, B.; Morkved, T. L.; Meron, M.; Huang, Z.; Viccaro, P.J .; J aeger, H. M.; Williams, S. M.; Schlossman, M. L. J . Appl. Phys. 1999, 85, 3180.

(15) Fink, Y.; Urbas, A. M.; Bawendt, M. G.; J oannopoulos, J . D.; Thomas, E. L. J . Lightwave Technol. 1999, 17, 1963.

(16) Fogg, D. E.; Radzilowski, L. H.; Blanski, R.; Schrock, R. R.; Thomas, E. L. Macromolecules 1997, 30, 417.

(17) Fogg, D. E.; Radzilowski, L. H.; Dabbousi, B. O.; Schrock, R. R.; Thomas, E. L.; Bawendi, M. G. Macromol ecules 1997, 30, 8433.

(18) Mattoussi, H.; Radzilowski, L. H.; Dabbousi, B. O.; Fogg, D. E.; Schrock R. R.; Thomas, E. L.; Rubner, M. F.; Bawendi, M. G. J . Appl. Phys. 1999, 86, 4390.

(19) Tsutsumi, K.; Funaki, Y.; Hirokawa, Y.; Hashimoto, T. Langmuir 1999, 15, 5200.

(20) Sevink, G. J . A.; Zvelindovsky, A. V.; van Vlimmeren, B. A. C.; Maurits, N. M.; Fraaije J . G. E. M. J . Chem. Phys. 1999, $110,2250$.

(21) Ginzburg, V. V.; Qiu, F.; Balazs, A. C. Polymer 2002, 43, 461.

(22) Ginzburg, V. V.; Gibbons, C.; Qiu, F.; Peng, G.; Balazs, A. C. Macromol ecules 2000, 33, 6140.

(23) Huh, J .; Ginzburg, V. V.; Balazs, A. C. Macromol ecules 2000, $33,8085$.

(24) Thompson, R. B.; Ginzburg, V. V.; Matsen, M. W.; Balazs, A. C. Science 2001 292, 2469.

(25) Matsen, M. W.; Bates, F. S. Macromolecules 1996, 29, 1091 and references therein.

(26) Tarazona, P. Mol. Phys. 1984, 52, 81.

(27) Somoza, A. M.; Tarazona, P. J . Chem Phys. 1989, 91, 517.

(28) Matsen, M. W.; Schick, M. Phys. Rev. Lett. 1994, 72, 2660.

(29) Carnahan, N. F.; Starling, K. E. J . Chem Phys. 1969, 51, 635.

(30) Matsen, M. W.; Barrett, C. J . Chem Phys. 1998, 109, 4108.

(31) Drolet, F.; Fredrickson, G. H. Phys. Rev. Lett. 1999, 83, 4317.

(32) Drolet, F.; Fredrickson, G. H. Macromolecules 2001, 34, 5317. The algorithm described in this paper follows closely that of Drolet and Fredrickson as presented in their Macromol ecules paper, more so than their PRL publication which we followed in our original study. ${ }^{24}$

(33) Bohbot-Raviv, Y.; Wang, Z.-G. Phys. Rev. Lett. 2000, 85, 3428.

(34) Press: W. H.; Flannery, B. P.; Teukolsky, S. A.; Vetterling, W. T. Numerical Recipes; Cambridge University Press: Cambridge, England, 1989.

(35) If the differences in the free energies are not significantly large, all phases should be considered more or less possible, and compared further with more accurate techniques such as the spectral method of Matsen. ${ }^{25}$ In our trials, we found that runs with different initial fields tended to robustly produce the equilibrium phase.

(36) We find that the minority domains are susceptible to small elliptical deformations, and consequently our simulations result in noncylindrical domains. Nevertheless, we believe the stable state is cylindrical, although our free energies are not sufficiently accurate to confirm this.

(37) Pickett, G. T.; Gross, M.; Okuyama, H. Phys. Rev. Lett. 2000, $85,3652$.

(38) Ulrich, R.; Du Chesne, A.; Templin, M.; Wiesner, U. Adv. Mater. 1999, 11, 141.

MA011563D 